\title{
The first 7 years of the metropolitan fire brigade emergency responder program - an overview of incidents attended
}

This article was published in the following Dove Press journal:

Open Access Emergency Medicine

9 October 2010

Number of times this article has been viewed

\author{
Malcolm J Boyle' \\ Brett Williams' \\ Colin Bibby ${ }^{2}$ \\ Allan Morton ${ }^{2}$ \\ Chris Huggins' \\ 'Department of Community \\ Emergency Health and Paramedic \\ Practice, Monash University, \\ Frankston, Victoria, Australia; \\ ${ }^{2}$ Emergency Medical Services, \\ Metropolitan Fire and Emergency \\ Services Board, Richmond,Victoria, \\ Australia
}

Purpose: The Melbourne Metropolitan Fire and Emergency Services Board (MFESB) was the first fire service in Australia to implement a service-wide emergency medical response (EMR) program in 2001. No additional scientific analysis of the first responder program has been reported since the pilot program. The objective of this study was to report the first 7 years of responses by firefighters as first responders.

Patients and methods: The MFESB have three separate datasets with cardiac arrest information: (i) callout record; (ii) patient care record; and (iii) cardiac arrest record, including data from the automatic external defibrillator. Descriptive statistics were used to summarize the demographic and specific outcome data. Ethics approval was granted.

Results: A total of 8227 incidents were attended over the first 7 years. The most incidents attended were cardiac arrest 54\% $(n=4450)$ followed by other medical 19\% $(n=1579)$, and drug overdose $11 \%(n=908)$; the remainder were $<10 \%$ each. Sixty-three percent of incidents involved males. Average age was 57.2 years, median age 63 years, range from $<1$ month to 101 years; average response time was 6.1 minutes, median response time 5.6 minutes, range from 9 seconds to 31.5 minutes. Firefighters provided "initial care" in $57 \%$ and assisted in $26 \%$ of the incidents. Firefighters spent on average 4.8 minutes with the patient before handing over to paramedics; median 3.9 minutes, range of a few seconds to 39.2 minutes.

Conclusion: This study suggests that the MFESB EMR program is providing firefighter first responders to emergency situations in a short timeframe to assist the ambulance service.

Keywords: emergency medical services, fire department, cardiac arrest, first responder

\section{Introduction}

Although the use of firefighters as first responders in the international prehospital setting is not new, the use of and reporting of the Melbourne Metropolitan Fire and Emergency Services Board (MFESB) emergency medical responder (EMR) program experience is new.

The use of firefighters as "first responders" to acute medical incidents, especially cardiac arrests, commenced in the mid-1980s in the USA ${ }^{1}$ and in the late 1980s in Canada. ${ }^{2}$ Firefighters and other emergency service workers were used as first responders to decrease the time from collapse to defibrillation, ${ }^{1-3}$ which demonstrated an improvement in patient outcomes.

In 1994 the Victorian Public Bodies Review Committee recommended that the Metropolitan Fire Brigade expand its role to include an emergency "first responder" role for acute medical conditions, including cardiac arrest, to support the then Metropolitan Ambulance Service. 
In 1998 the Victorian Government approved a 6-month pilot study to investigate whether the simultaneous dispatch of fire and ambulance resources to acute medical emergencies, including cardiac arrest, could lead to decreased response times and thereby improve the patient's chance of survival. The Emergency Medical Response (EMR) First Responder program pilot, as it was called, commenced on July 14, 1998 and concluded on January 14, 1999. The pilot data demonstrated a decrease in emergency vehicle response time as well as time to defibrillation in the pilot area. However, there were an insufficient number of cardiac arrests to demonstrate that the program definitely improved patient outcome from cardiac arrest.

In early February 2000 the Victorian Government extended the pilot study for another 12 months to cover the entire MFESB area of operation. The results from the extended pilot study confirmed that firefighters as first responders to cardiac arrests did improve patient outcomes ${ }^{4,5}$ and that the majority of firefighters thought this was a worthwhile use of fire personnel and resources. ${ }^{6}$ The Victorian Government confirmed the inclusion of the EMR First Responder as core MFESB business in December 2001.

Following publication of the pilot EMR results and an analysis of the first 12 months of the EMR program, ${ }^{5}$ the MFESB has published limited results regarding the EMR program. No further independent scientific analysis of the success of the program over the 7 years has been undertaken. The objective of this study was to report the first 7 years of responses by firefighters as first responders.

\section{Material and methods}

\section{Study design}

This study was a retrospective case review of all EMR incidents attended by the MFESB over the first 7 years of the program.

\section{Study population}

The MFESB services an area of approximately $1100 \mathrm{~km}^{2}$ with a population of approximately two million people. The MFESB has 51 fire stations servicing the area. Each firefighter undertakes an 8-day training course, with 1-day refresher training every 3 years, monthly skills maintenance, and regular incident follow up by Ambulance Victoria paramedics.

Any patient who was attended to by the MFESB as part of the EMR, between March 1, 2001 and February 28, 2008 was eligible for inclusion into the study. Patient data were excluded from further analysis where the electronic record had insufficient information to make a judgment about the patient's problem and their management.

\section{Study processes}

The MFESB has three data files that contain all relevant information about each EMR incident attended; these included the callout data file, the patient care record data file, and the cardiac arrest data file. All files were available in a Microsoft Excel $^{\circledR}$ file format.

There is also an electrocardiogram (ECG) file obtained from the automatic external defibrillator (AED) following each cardiac arrest. This ECG file contains the cardiac rhythms, relevant times, and other data pertinent to analysis of the cardiac arrest management.

The data was "cleaned" to ensure there were no duplicate records and that any outliers were a result of natural variation and not inaccurate data entry.

\section{Ethics}

Ethics approval for the study was granted by the Monash University Standing Committee on Ethics in Research Involving Humans.

Table I Incident type attended, by year of the program

\begin{tabular}{|c|c|c|c|c|c|c|c|c|}
\hline \multirow[t]{2}{*}{ Incident type } & \multicolumn{8}{|c|}{ Year of the program } \\
\hline & $\mathbf{I}$ & 2 & 3 & 4 & 5 & 6 & 7 & Tota \\
\hline Trauma incident & 119 & 125 & 110 & 100 & 58 & 73 & 77 & 662 \\
\hline Drug overdose & 88 & 155 & 158 & 147 & 63 & 107 & 190 & 908 \\
\hline Drowning/near drowning & 7 & 9 & 9 & 2 & 5 & 9 & 17 & 58 \\
\hline Suffocation & 29 & 47 & 31 & 49 & 33 & 44 & 49 & 282 \\
\hline Electric shock & 7 & 4 & 2 & 4 & 3 & 4 & 5 & 29 \\
\hline Gas/smoke inhalation & 34 & 29 & 25 & 21 & 16 & 28 & 30 & 183 \\
\hline Burns & 13 & 10 & 16 & 7 & 6 & 8 & 16 & 76 \\
\hline Other medical & 194 & 229 & 206 & 180 & 169 & 265 & 336 & 1579 \\
\hline Cardiac arrest & 638 & 609 & 705 & 597 & 526 & 610 & 765 & 4450 \\
\hline Total & 1129 & 1217 & 1262 & 1107 & 879 & $1 / 48$ & 1485 & 8227 \\
\hline
\end{tabular}


Table 2 Type of action, by year of the program

\begin{tabular}{|c|c|c|c|c|c|c|c|c|}
\hline \multirow[b]{2}{*}{ Action type } & \multicolumn{8}{|c|}{ Year of the program } \\
\hline & $\mathbf{I}$ & 2 & 3 & 4 & 5 & 6 & 7 & Total \\
\hline Provide care & 613 & 601 & 648 & 545 & 391 & 493 & 629 & 3920 \\
\hline Assist only & 220 & 247 & 221 & 236 & 181 & 280 & 392 & 1777 \\
\hline Investigate/observe & 244 & 224 & 228 & 189 & 182 & 197 & 249 & 1513 \\
\hline Downgraded/cancelled & 4 & 1 & I & 1 & 0 & 0 & 1 & 8 \\
\hline Total & $|08|$ & 1073 & 1098 & $97 \mid$ & 754 & 970 & $|27|$ & 7218 \\
\hline
\end{tabular}

\section{Data analysis}

The data were analyzed using SPSS (Statistical Package for the Social Sciences Version 17.0, SPSS Inc., Chicago, Illinois, USA). Descriptive statistics, including means and medians were used to summarize the demographic and specific outcome measure data.

\section{Results}

The MFESB attended a total of 8227 incidents as part of the EMR program over the 7-year period. See Table 1 for total EMR incidents attended for each year of the program. Gender distribution was available for 7917 incidents; $63.3 \%$ were male and $36.7 \%$ female. The mean age was 57.2 years, median 63 years, range of several weeks to 101 years of age.

The MFESB categorized their responses into 11 different categories, including cardiac arrest. The number of incidents attended by the program year can be seen in Table 1 .

There were 7218 incidents where the action type could be identified. The firefighters provided "initial care" in 54\% of the incidents they attended and "assisted" in a further $26 \%$ of the incidents attended. See Table 2 for the numbers for each action type by year of the program.

There were 6829 incidents where a response time could be determined, with 1398 incidents excluded as one or both of the required times to calculate the response time was missing. The average response time over the 7 years was 6.14 minutes (95\% confidence interval [CI] 6.07-6.20 minutes) with a median response time of 5.61 minutes, 90th percentile of 8.69 minutes. The response time range was from 9 seconds to 31.5 minutes. For the average and median response time by year of the program, see Table 3 .
The majority (39.1\%) of patients were unconscious with no signs of life on arrival of the firefighters, with $14.4 \%$ of patients unconscious with signs of life. For the condition of all patients, see Table 4 .

There were 3418 incidents where a "with patient time" could be determined, with 4859 incidents excluded as one or both of the required times to calculate the "with patient time" was missing. Firefighters spent on average 4.83 minutes (95\% CI 4.69-4.98 minutes) with the patient before handing over to paramedics, median 3.9 minutes, range from 6 seconds to 39.2 minutes. For cardiac arrest incidents, there were 1987 incidents where a "with patient time" could be determined, with 2463 incidents excluded as one or both of the required times to calculate the "with patient time" was missing. The firefighters spent on average 4.62 minutes (95\% CI 4.44-4.81 minutes) with the cardiac arrest patient before handing over to paramedics, median 3.7 minutes, range from 12 seconds to 36.5 minutes.

The majority of incidents occurred in the morning, between $7 \mathrm{am}$ and 9am, with a second peak between $4 \mathrm{pm}$ and 6pm in the late afternoon (see Figure 1).

Most of these incidents occurred on a Saturday, with the least occurring on a Monday and Thursday, and with most incidents attended in October and the least in February.

\section{Discussion}

The results from the review of the first 7 years of the MFESB EMR suggest that firefighters have an average and median response time that is comparable, or better, than other state and international first responders. The aim of using the MFESB as first responders was to decrease the response time

Table 3 Average, median and 90th percentile response time for incidents, by year of the program

\begin{tabular}{lllllllll}
\hline & \multicolumn{3}{l}{ Year of the program } & & & \\
\cline { 2 - 9 } & $\mathbf{I}$ & $\mathbf{2}$ & $\mathbf{3}$ & $\mathbf{4}$ & $\mathbf{5}$ & $\mathbf{6}$ & $\mathbf{7}$ & Total \\
\hline Average response time & 6.01 & 6.22 & 5.95 & 6.1 & 6.23 & 6.42 & 6.02 & $\mathbf{6 . 1 4}$ \\
Median response time & 5.4 & 5.5 & 5.59 & 5.6 & 5.66 & 5.85 & 5.71 & $\mathbf{5 . 6 1}$ \\
90th percentile response time & 8.57 & 9.01 & 8.26 & 8.77 & 9.19 & 9.4 & 8.31 & $\mathbf{8 . 6 9}$ \\
\hline
\end{tabular}


Table 4 Patients condition on arrival of the firefighters, by year of the program

\begin{tabular}{|c|c|c|c|c|c|c|c|c|}
\hline \multirow[t]{2}{*}{ Action type } & \multicolumn{8}{|c|}{ Year of the program } \\
\hline & $\mathbf{I}$ & 2 & 3 & 4 & 5 & 6 & 7 & Total \\
\hline Conscious & 304 & 301 & 294 & 263 & 180 & 312 & 358 & 2012 \\
\hline Unconscious but signs of life & 126 & 197 & 183 & 164 & 117 & 155 & 240 & 1182 \\
\hline Unconscious with no signs of life & 450 & 443 & 498 & 471 & 368 & 438 & 546 & 3214 \\
\hline Obviously deceased & 192 & 200 & 208 & $|5|$ & 153 & 162 & 195 & $|26|$ \\
\hline Not stated & 57 & 76 & 79 & 58 & 61 & 81 & 146 & 558 \\
\hline Total & 1129 & 1217 & 1262 & II 07 & 879 & II48 & 1485 & 8227 \\
\hline
\end{tabular}

to urgent incidents, predominately cardiac arrests, and to provide basic life support and early defibrillation to those in cardiac arrest.

The response time to urgent incidents by the MFESB when compared with Ambulance Victoria - Metropolitan (AV-M) is considerably less in the 50th and 90th percentile. The MFESB 50th and 90th percentile response times have remained relatively constant over the 7 years, whereas those for AV-M have increased. The AV-M 50th percentile response time has increased from 8 minutes in 2001-2002 to 9.5 minutes in 2007-2008. Whilst the AV-M 90th percentile response time has increased from 14 minutes in 2001-2002 to 16.5 minutes in $2007-2008$. $^{7,8}$ Other scientific literature supports the notion of longer response times by AV-M over time. ${ }^{9-12}$ The AV-M annual reports do not contain mean response time data.

The MFESB EMR program has demonstrated better response times than the ambulance service to actual and potential cardiac arrest patients over the first 7 years of the program, in line with the "chain of survival" concept first describe by Cummins et al in $1991 .^{13}$ The basis behind the concept was: i) the early access to recognition of cardiac

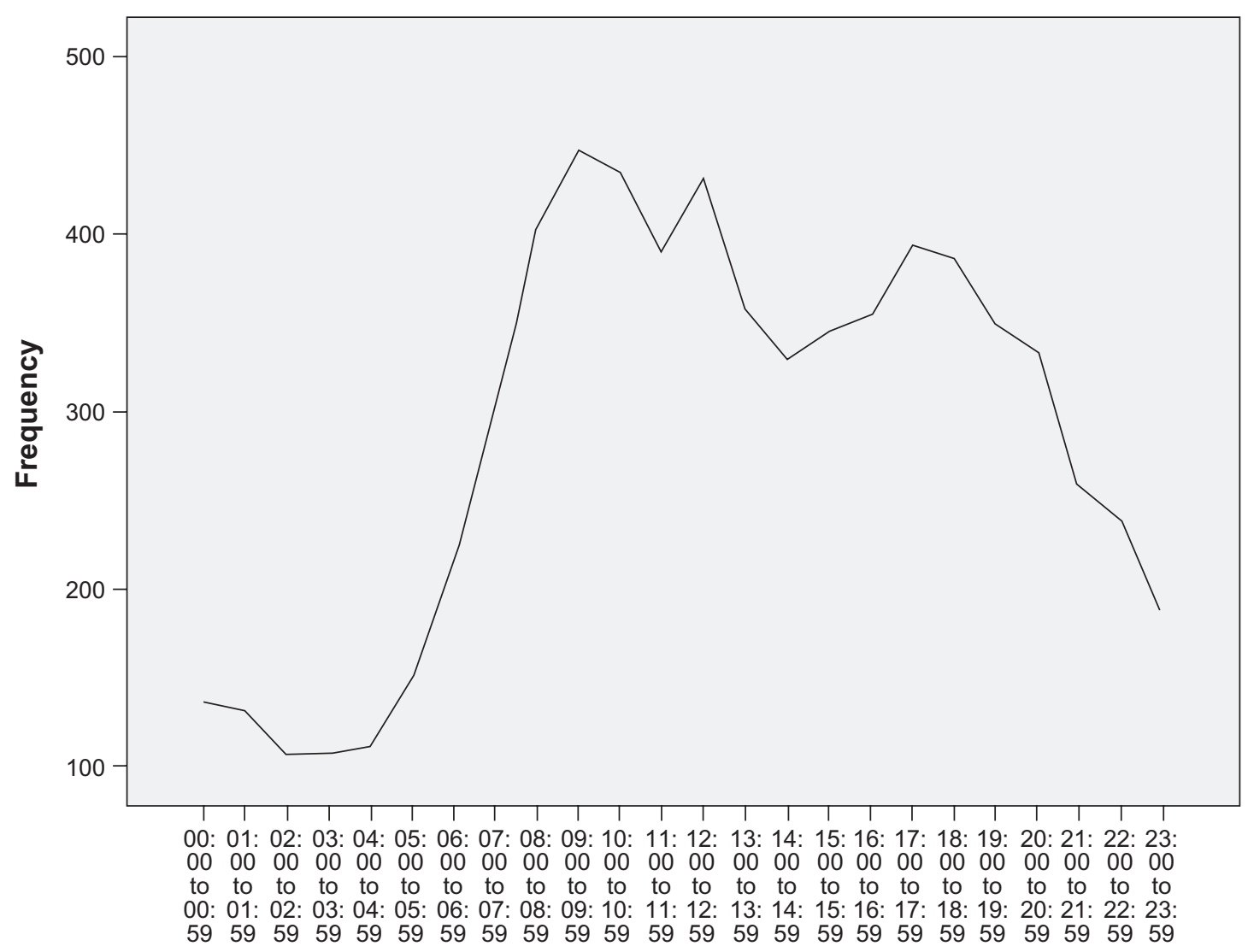

Hour of the day

Figure I Incident response by hour of the day. 
arrest and calling for help; ii) early commencement of cardiopulmonary resuscitation (CPR); iii) early access to defibrillation; and iv) early access to advanced life support. ${ }^{13}$ Studies have shown that early access to CPR and defibrillation improves the survivability of the cardiac arrest patient. ${ }^{14-16}$ With the advent of AEDs in the mid to late 1980 s, the ability for lay people with minimal training to act as "first responders" to cardiac arrests was possible. Within Victoria there are several "first responder" type programs, including the one operated by the MFESB, which support the state ambulance service. ${ }^{17,18}$

The predominance of cardiac arrest responses also equates to the patient's condition on arrival of the firefighters, with most, $68 \%(n=3028)$, patients unconscious with no signs of life. This in some ways correlates with the action provided by the firefighters, $54.3 \%(\mathrm{n}=3920)$ providing actual initial care or assisting the paramedics $24.6 \%$ ( $n=1777)$ who arrived just prior, or at the same time, as the firefighters.

With early access already proven to increase patient survivability, the response time becomes a critical time element within the total time from collapse to defibrillation. In a previous Melbourne based cardiac arrest study by Bernard which looked at cardiac arrest management by the then Metropolitan Ambulance Service, the average response time was found to be 9.4 minutes. ${ }^{9}$ In this study we found the average response time by firefighters to be 6.14 minutes with a median response time of 5.61 minutes. In the EMR pilot study, Smith et al reported the ambulance response time as 7.61 minutes and the first on scene (fire or ambulance) as 5.85 minutes. There was no individual fire response time reported. ${ }^{4}$ Some first responders have very low average and median response times, less than 4 minutes, primarily due to the small geographic area they cover and the calculated distribution of resources to cover that area; $;^{17,19-21}$ whereas cardiac arrests responded to by ambulances only have predominately longer response times, around the 9 minute average or higher. ${ }^{9,19,20,22,23}$ The response times by MFESB firefighters in their area of operation may be decreased if there was a dual fire appliance response like that which occurs for actual/potential fires.

This study is the basis for further investigation into the effectiveness of the MFESB EMR program. Further work will be carried out on the MFESB EMR data to ascertain what cardiac rhythm cardiac victims were in on arrival of the firefighter, additional times (including time to defibrillation), and survival rates to discharge from hospital for cardiac arrest patients.

\section{Conclusion}

The findings from this study demonstrate that the MFESB EMR program is responding primarily to cardiac arrests. As a result of the EMR program, defibrillator-equipped firefighters are responding to the scene of a potential or actual cardiac arrest in a short timeframe within the MFESB area of operation.

\section{Acknowledgment/disclosure}

We gratefully acknowledge the Windermere Foundation for funding this project. No conflict of interest is declared for any of the authors.

\section{References}

1. Weaver WD, Copass MK, Hill DL, Fahrenbruch C, Hallstrom AP, Cobb LA. Cardiac arrest treated with a new automatic external defibrillator by out-of-hospital first responders. Am J Cardiol. 1986;57(13): 1017-1021.

2. Shuster M, Keller JL. Effect of fire department first-responder automated defibrillation. Ann Emerg Med. 1993;22(4):721-727.

3. Mosesso VN Jr, Davis EA, Auble TE, Paris PM, Yealy DM. Use of automated external defibrillators by police officers for treatment of out-of-hospital cardiac arrest. Ann Emerg Med. 1998;32(2):200-207.

4. Smith KL, Peeters A, McNeil JJ. Results from the first 12 months of a fire first-responder program in Australia. Resuscitation. 2001;49(2): 143-150.

5. Smith KL, McNeil JJ. for the Emergency Medical Response Steering Committee. Cardiac arrests treated by ambulance paramedics and fire fighters. Med J Aust. 2002;177(6):305-309.

6. Smith K, Rich D, Pinol JP, Hankin J, McNeil J. Acceptance of a medical first-responder role by fire fighters. Resuscitation. 2001;51(1):33-38.

7. Metropolitan Ambulance Service. Metropolitan Ambulance Service 2007-2008 Annual Report. Doncaster: Metropolitan Ambulance Service; 2008.

8. Metropolitan Ambulance Service. Metropolitan Ambulance Service 2005-2006 Annual Report. Doncaster: Metropolitan Ambulance Service; 2006.

9. Bernard S. Outcome from prehospital cardiac arrest in Melbourne, Australia. Emerg Med (Fremantle). 1998;10(1):25-29.

10. Jackson P, Cameron P. Prehospital defibrillation in Geelong. Emerg Med. 1993;5:184-187.

11. Jennings P, Pasco J. Survival from out-of-hospital cardiac arrest in the Geelong region of Victoria, Australia. Emerg Med (Fremantle). 2001;13(3):319-325.

12. Jennings PA, Cameron P, Walker T, Bernard S, Smith K. Outof-hospital cardiac arrest in Victoria: rural and urban outcomes. Med J Aust. 2006;185(3):135-139.

13. Cummins RO, Ornato JP, Thies WH, Pepe PE. Improving survival from sudden cardiac arrest: the "chain of survival" concept. A statement for health professionals from the Advanced Cardiac Life Support Subcommittee and the Emergency Cardiac Care Committee, American Heart Association. Circulation. 1991;83(5):1832-1847.

14. Herlitz J, Engdahl J, Svensson L, Angquist KA, Young M, Holmberg S Factors associated with an increased chance of survival among patients suffering from an out-of-hospital cardiac arrest in a national perspective in Sweden. Am Heart J. 2005;149(1):61-66.

15. Marenco JP, Wang PJ, Link MS, Homoud MK, Estes NA 3rd. Improving survival from sudden cardiac arrest: the role of the automated external defibrillator. JAMA. 2001;285(9):1193-1200.

16. White RD, Bunch TJ, Hankins DG. Evolution of a community-wide early defibrillation programme experience over 13 years using police/fire personnel and paramedics as responders. Resuscitation. 2005;65(3):279-283. 
17. Chan T, Braitberg G, Elbaum D, Taylor DM. Hatzolah emergency medical responder service: to save a life. Med J Aust. 2007;186(12): 639-642.

18. Wassertheil J, Keane G, Fisher N, Leditschke JF. Cardiac arrest outcomes at the Melbourne Cricket Ground and shrine of remembrance using a tiered response strategy - a forerunner to public access defibrillation. Resuscitation. 2000;44(2):97-104.

19. Callaham M, Braun O, Valentine W, Clark DM, Zegans C. Prehospital cardiac arrest treated by urban first-responders: profile of patient response and prediction of outcome by ventricular fibrillation waveform. Ann Emerg Med. 1993;22(11):1664-1677.

20. Sweeney TA, Runge JW, Gibbs MA, et al. EMT defibrillation does not increase survival from sudden cardiac death in a two-tiered urbansuburban EMS system. Ann Emerg Med. 1998;31(2):234-240.
21. Ma MH, Chiang WC, Ko PC, et al. Outcomes from out-of-hospital cardiac arrest in Metropolitan Taipei: does an advanced life support service make a difference? Resuscitation. 2007;74(3):461-469.

22. Ong ME, Ng FS, Anushia P, et al. Comparison of chest compression only and standard cardiopulmonary resuscitation for out-of-hospital cardiac arrest in Singapore. Resuscitation. 2008;78(2):119-126.

23. Becker L, Gold LS, Eisenberg M, White L, Hearne T, Rea T. Ventricular fibrillation in King County, Washington: A 30-year perspective. Resuscitation. 2008;79(1):22-27.

\section{Publish your work in this journal}

Open Access Emergency Medicine is an international, peer-reviewed, open access journal publishing original research, reports, editorials, reviews and commentaries on all aspects of emergency medicine. The manuscript management system is completely online and includes a very quick and fair peer-review system, which is all easy to use.
Visit http://www.dovepress.com/testimonials.php to read real quotes from published authors. 